\title{
MDP-based universal adhesive system irradiated with Er,CR:YSGG: Analysis of its performance up to 6 months
}

\author{
Giovanna Speranza ZABEU ${ }^{1}$, Letícia Ferreira Freitas BRIANEZZI'1, Rafael Simões GONÇALVES ${ }^{1}$, \\ Rafael Massunari MAENOSONO ${ }^{1}$, Regina Guenka PALMA-DIBB ${ }^{2}$, Linda WANG ${ }^{1}$ and Sérgio Kiyoshi ISHIKIRIAMA ${ }^{1}$ \\ ${ }^{1}$ Department of Operative Dentistry, Endodontics and Dental Materials, Bauru School of Dentistry, University of São Paulo, Alameda Octávio Pinheiro \\ Brisolla, 9-75, zip code 17012-901, Bauru, SP, Brazil \\ ${ }^{2}$ Department of Restorative Dentistry, Dental School of Ribeirão Preto, University of São Paulo, Avenida do Café, s/n' ${ }^{\circ}$ zip code 14040-904, Ribeirão \\ Preto, SP, Brazil \\ Corresponding author, Sérgio Kiyoshi ISHIKIRIAMA; E-mail: serginho@usp.br
}

This study aimed to analyze the interaction of a MDP-based universal dentin bonding system (DBS) with Er, Cr: YSGG laser irradiation, measuring the microtensile bond strength to dentin over a six-month period. The experimental design involved three factors: DBS (Adper Scotchbond Universal; Clearfil SE Bond, Adper Scotchbond Multipurpose and Adper Single Bond 2), laser (Control and Er, Cr: YSGG), and time (initial- 7 days and 6 months). Eighty dentin samples from molars were prepared ( $n=10)$ with laser irradiation after primer and DBS application. After 7 days, were subjected to micro tensile bond strength test. The data were analyzed by three-way ANOVA and Tukey tests $(p<0.05)$. Both DBS and laser significantly affected the bonding performance and their interaction was statistically significant $(p=0.0194)$. The self-etching mode of the MDP-based universal DBS maintained the bond strength on dentin irradiated with ER, Cr: YSGG after 6 months, while bonding with all other DBS deteriorated.

Keywords: Dentin-bonding agents, Laser, Micro tensile bond strength, Universal adhesive

\section{INTRODUCTION}

Bonding to dentin occurs via a complex mechanism as it involves dynamic biological tissues ${ }^{1-3)}$. Therefore, different categories of dentin bonding systems were developed to overcome the main challenges regarding the establishment of a long-term interface between these polymeric materials and the biological tissues ${ }^{1.7)}$.

To this end, understanding the compositional and structural formation as well as the mineral content and organic matrix of dentin is needed to guide the development of improved adhesive materials ${ }^{1,3,4,8)}$. Novel materials that consider the interactions between polymers and the dentin under clinical conditions have potential to exhibit enhanced performance ${ }^{2,6,9,10)}$.

Regarding dentin bonding systems (DBS), universal or multi-mode DBS have been used in many investigations $\mathrm{s}^{4,5,11,12)}$. The most attractive feature of these systems is the possibility to use them as part of etch-and-rinse or self-etching techniques. Some systems also provide the choice of dry or moist bonding technique protocols.

With previously reported evidence of good performance, the use of universal DBS in combination with other strategies to improve the interaction between substrate and MDP-based DBS has become increasingly popular ${ }^{2,4-8)}$. Stable chemical bonding is also achieved ${ }^{13,14)}$ and laser association is a promising tool that has already been used to enhance bonding to dentin ${ }^{15-17)}$.

Initially, several investigations assessed the effect of the use of erbium lasers for dental cavity treatments ${ }^{18-20)}$, to morphologically modify the enamel and dentin substrate through interactions with hard dental tissue ${ }^{21,22}$. Its use has been widely reported in the literature ${ }^{23-25)}$. The erbium, chromium: yttrium scandium gallium garnet (Er, Cr: YSGG) laser irradiates at 2,790 $\mathrm{nm}$, where the maximum absorption peak of hydroxyapatite and water occurs. This allows the laser to cut hard tissues such as bone, enamel, and dentin $^{26)}$. Irradiated on dentin can create a substrate free of the smear layer, denaturing the organic content, and reducing the solubility of hydroxyapatite, which is suggested to improve the adhesive interface ${ }^{27,28)}$. Controversially, some studies have observed flaws in the morphological modifications of irradiated dentin, including opened dentinal tubules, fissures, and cracks on the peritubular dentin which appeared protruded on dentin surface ${ }^{29,30)}$. The use of a laser with a wavelength compatible with the water absorption peak could be an interesting strategy for the removal of residual water present within the dentin structure responsible for the hydrolytic degradation that occurs over time, decreasing the clinical time of restoration ${ }^{1,8,17)}$.

Previous studies assumed that laser irradiation could provide long lasting dental bonding performance if used during, instead of before, DBS application. In 1999 Gonçalves et $a l .{ }^{15)}$ used irradiation with an experimental high-power laser (Nd: YFL) after adhesive application before light-curing and obtained promising results with increased shear bonding strength to dentin. Marimoto et al. ${ }^{16)}$ used Nd: YAG $(1,064 \mathrm{~nm})$ high-power laser to compare the bond strength of two-step etch-and-rinse systems and self-etch systems irradiated under the same conditions. The authors also observed increased bonding strength when the adhesives were irradiated. ${ }^{16)}$ Maenosono et al. ${ }^{17)}$ proposed the use of a diode laser (970 
$\mathrm{nm}$ ), which is portable and inexpensive. In their study, the bond strength of the simplified dental adhesive was evaluated, showing increased bond strength for the laser irradiated groups. Based on these investigations, the use of lasers for etch-and-rinse DBS improved the formation of more uniform hybrid layers ${ }^{17}$. This is one of the most accepted hypotheses regarding the effective use of lasers with solvated etch-and-rinse systems ${ }^{17}$.

The use of adhesives containing functional monomers with the ability to promote chemical interaction with calcium ions has become the more advocated strategy recently ${ }^{31}$. Among functional monomers on the market, 10-methacryloyloxydecyl dihydrogen phosphate (10-MDP) stands out because it promotes chemical adhesion with hydroxyapatite and forms stable ionic bonds with dentin in an aqueous environment ${ }^{32)}$. Despite its use in self-etching DBS, it has been a relevant ingredient in universal DBS.

Therefore, lasers can be used with universal DBS considering that they could facilitate the penetration and involvement of these agents and aid in their incorporation in modified substrates. Ayar and Erdemir ${ }^{19)}$ investigated the adjunctive use of a universal bonding system with Er, Cr: YSGG on the enamel surface with interesting performance.

The purpose of this study was to analyze the effect of an MDP-based universal adhesive irradiated with Er, Cr: YSGG on dentin bonding over the course of 6 months.

\section{MATERIALS AND METHODS}

\section{Experimental design}

This in vitro study involved three major factors: the DBS in four levels (Adper Scotchbond ${ }^{\mathrm{TM}}$ Universal [SU]-10MDP based; Clearfil ${ }^{\mathrm{TM}}$ SE Bond [CSE]-10-MDP based; Adper $^{\mathrm{TM}}$ Scotchbond Multipurpose [MP]-methacrylatebased, and Adper ${ }^{\mathrm{TM}}$ Single Bond 2 [SB]-methacrylatebased); treatment in two levels (No irradiation-Control $[\mathrm{C}]$ and Er, Cr: YSGG laser irradiation [E]), and time (initial [I] and 6 months [6m]). The quantitative response variable was the bond strength determined using micro tensile test. The failure mode was also analyzed using portable digital microscopy at a $40 \times$ magnification.

\section{Specimen preparation}

A total of 80 sound human third molars were extracted for surgical reasons after consent and approval by the local Ethical Committee (protocol number 49812415.1.0000.5417), and were randomized using Excel software (Microsoft Office ${ }^{\circledR}$, Redmond, WA, USA) according to the dimensions of exposed dentin area into eight groups $(n=10)$. Teeth were stored in $0.1 \%$ tymol solution. After the teeth were completely cleaned, the crowns were transversely sectioned on the occlusal third to expose the dentin using a low-speed diamond saw (Isomet ${ }^{\mathrm{TM}}$ Low Speed Saw ${ }^{\mathbb{Q}}$, Buehler, Lake Bluff, IL, USA) with a water-cooled diamond disc (Extec, Enfield, CA, USA). The remaining enamel was removed using \#320 grit silicon carbide paper (Carbimet Paper
Discs, Buehler) on a polishing machine (Arotec, Cotia, $\mathrm{SP}$, Brazil). The samples were polished for $30 \mathrm{~s}$ with a \#600 grit silicon carbide paper to simulate smear layer formation and stored in deionized water at $37{ }^{\circ} \mathrm{C}$ until the moment of DBS application.

\section{DBS application and laser treatment}

Two etch-and-rinse adhesives, one self-etch adhesive, and one universal adhesive were tested. All DBS were applied according to the manufacturers' instructions (Table 1). For the etch-and-rinse adhesives, 37\% phosphoric acid (Dentsply, Catanduva, SP, Brazil) was applied for $15 \mathrm{~s}$, rinsed for the same time, and the dentin was then dried with absorbent paper (wet technique). For the MP and CSE, a single coat of primer was applied, and an air stream was gently applied for $5 \mathrm{~s}$ at a standardized distance of $5 \mathrm{~cm}$. Subsequently, one coat of adhesive was applied, and the excess was removed. For SB, two coats of primer/bond were applied, and an air stream was gently applied for $5 \mathrm{~s}$ at a distance of $5 \mathrm{~cm}$. For the universal adhesive (SU), a single coat of adhesive was actively applied for $20 \mathrm{~s}$, the excess was removed, and an air stream was gently applied for $5 \mathrm{~s}$ at a standardized distance of $5 \mathrm{~cm}$. All adhesives were light-cured for $10 \mathrm{~s}$ using an LED Blue Star 2 (1,000 $\mathrm{mW} / \mathrm{cm}^{2}$, Microdont, São Paulo, SP, Brazil) device.

The Er, Cr: YSGG laser (Water Lase iPlus, Biolase, Irvine, CA, USA) was activated after primer application at a distance of $3 \mathrm{~mm}$ from the surface substrate (noncontact mode), $90^{\circ}$ inclination, and standardized by XY table after automatic scanning of the area (BioPDI, São Carlos, SP, Brazil). The table facilitated an automatic zigzag scan, where the displacement of the $\mathrm{X}$ axis was determined by the extent of the test area and that of the $\mathrm{Y}$ axis was based on the thickness of the optical fiber tip (Fig. 1). The time was standardized according to the largest specimen so that the entire dentin area of all specimens received irradiation with the same energy density. The standardized time between the beginning of the irradiation until the moment of polymerization was $60 \mathrm{~s}$. For control groups, it was waited $60 \mathrm{~s}$ before lightcuring to standardize the time between all specimens. The detailed parameters used for laser irradiation are listed in Table 2.

Lastly, the specimens were restored using Filtek Z250 (3M ESPE, St Paul, MN, USA) in three consecutives $1.5 \mathrm{~mm}$ increments. The specimens were stored in deionized water at $37^{\circ} \mathrm{C}$ for 7 days. Subsequently, the specimens were perpendicularly sectioned to the occlusal dentin with a low-speed diamond saw (Isomet, Buehler) to obtain resin-dentin sticks with $0.64 \mathrm{~mm}^{2}$ average cross-sectional dimensions. Twenty-five sticks were obtained from each tooth, approximately. The sticks were divided for the initial and 6-month groups. During the 6 months of storage, the sticks were kept in deionized water at $37^{\circ} \mathrm{C}$ that was replaced every 15 days.

\section{Micro tensile bond strength test}

The specimens were tested using an Instron 3342 universal testing machine (Illinois Tool Works, 
Table 1 Commercially available systems, their classification, compositions and application technique before polymerization

\begin{tabular}{|c|c|c|c|c|}
\hline $\begin{array}{l}\text { Dentin } \\
\text { Bonding }\end{array}$ & Manufacturer & $\begin{array}{l}\text { Classification/ } \\
\text { Lot number }\end{array}$ & Composition & Application technique \\
\hline $\begin{array}{l}\text { Adper }{ }^{\mathrm{TM}} \\
\text { Scotchbond } \\
\text { Multipurpose }\end{array}$ & $\begin{array}{l}\text { 3M ESPE, } \\
\text { St Paul, } \\
\text { MN, USA }\end{array}$ & $\begin{array}{l}\text { Three-step } \\
\text { etch-and-rinse } \\
\text { system/Primer: } \\
\text { N857445 Bond: } \\
\text { N843842 }\end{array}$ & $\begin{array}{l}\text { Primer: HEMA*, water, } \\
\text { copolymer of polyalcenoic acid. } \\
\text { Bond: HEMA*, Bis-GMA** } \\
\text { and camphorquinone }\end{array}$ & $\begin{array}{l}\text { 1. Etch dentin surface with } \\
\text { phosphoric acid } 37 \% \text { for } \\
15 \mathrm{~s} \\
2 . \text { Rinse for } 15 \mathrm{~s} \\
\text { 3. Gently dry with } \\
\text { absorbent paper } \\
\text { 4. Apply primer with a } \\
\text { microbrush } \\
\text { 5. Gently air-dry for } 5 \mathrm{~s} \\
\text { 6. Laser irradiation (for the } \\
\text { irradiated groups) } \\
\text { 7. Apply bond with a } \\
\text { microbrush and remove } \\
\text { excess }\end{array}$ \\
\hline $\begin{array}{l}\text { Adper }{ }^{\mathrm{TM}} \\
\text { Single Bond } 2\end{array}$ & 3M ESPE & $\begin{array}{l}\text { Two-step } \\
\text { Etch-and-rinse } \\
\text { system/ } \\
\text { N695410 }\end{array}$ & $\begin{array}{l}\text { HEMA*; Bis-GMA**, ethanol; } \\
\text { silane treated silica filler; } \\
\text { glycerol 1,3 dimethacrylates; } \\
\text { diuretanedimethacrylate and } \\
\text { copolymer of polyacrylic and } \\
\text { polyitaconic acids. }\end{array}$ & $\begin{array}{l}\text { 1. Etch dentin surface with } \\
\text { phosphoric acid } 37 \% \text { for } \\
15 \mathrm{~s} \\
\text { 2. Rinse for } 15 \mathrm{~s} \\
\text { 3. Gently dry with } \\
\text { absorbent paper } \\
\text { 4. Apply two coats of } \\
\text { the primer/bond with a } \\
\text { microbrush and remove } \\
\text { excess } \\
\text { 5. Gently air-dry for } 5 \mathrm{~s} \\
\text { 6. Laser irradiation (for the } \\
\text { irradiated groups) }\end{array}$ \\
\hline $\begin{array}{l}\text { Clearfil SETM } \\
\text { Bond }\end{array}$ & $\begin{array}{l}\text { Kuraray, } \\
\text { Okayama, } \\
\text { Japan. }\end{array}$ & $\begin{array}{l}\text { Two-step } \\
\text { self-etch } \\
\text { system/ } \\
\text { 9N0169 }\end{array}$ & $\begin{array}{l}\text { Primer: MDP***; HEMA**; } \\
\text { hydrophilic aliphatic } \\
\text { dimethacrylate; } \\
\text { dl-Camphorquinone; } \\
\text { N,N-Diethanol-p-toluidine; } \\
\text { Water. } \\
\text { Bond: MDP***; HEMA*; } \\
\text { Bis-GMA***; hydrophobic } \\
\text { aliphatic dimethacrylate; } \\
\text { dl-Camphorquinone; } \\
\text { N,N-Diethanol-p-toluidine; } \\
\text { colloidal silica. }\end{array}$ & $\begin{array}{l}\text { 1. Apply primer with a } \\
\text { microbrush for } 20 \mathrm{~s} \\
\text { 2. Gently air-dry for } 5 \mathrm{~s} \\
\text { 3. Laser irradiation (for the } \\
\text { irradiated groups) } \\
\text { 4. Apply bond with a } \\
\text { microbrush and remove } \\
\text { excess }\end{array}$ \\
\hline $\begin{array}{l}\text { Adper } \\
\text { Scotchbond } \\
\text { Universal }\end{array}$ & $\begin{array}{l}\text { 3M ESPE, } \\
\text { Seefeld, } \\
\text { Germany. }\end{array}$ & $\begin{array}{l}\text { Universal } \\
\text { system } \\
\text { (used as } \\
\text { one-step } \\
\text { self-etch } \\
\text { system with } \\
\text { wet-technique)/ } \\
643238\end{array}$ & $\begin{array}{l}\text { MDP***; HEMA*; Bis-GMA**; } \\
\text { silica treated silane; ethanol; } \\
\text { decamethylenedimethacrylate; } \\
\text { water; 1,10-decanediol } \\
\text { dimethacrylate; copolymer of } \\
\text { polyacrylic and polyitaconic } \\
\text { acids; Camphorquinone; } \\
\text { N,N-dimethylbenzocaine; } \\
\text { methacrylate } \\
\text { 2-dimethylmonoethyl; methyl } \\
\text { etyl ketone. }\end{array}$ & $\begin{array}{l}\text { 1. Apply bond actively for } \\
20 \mathrm{~s} \\
\text { 2. Gently air-dry for } 5 \mathrm{~s} \\
\text { 3. Laser irradiation (for the } \\
\text { irradiated groups) }\end{array}$ \\
\hline
\end{tabular}

*HEMA: 2-hydroxyethyl methacrylate

**Bis-GMA: Bisphenol A diglycidyl methacrylate

***MDP: 10-methacryloyloxydecyl dihydrogen phosphate 
Table 2 Parameters used for irradiation

\begin{tabular}{ll}
\multicolumn{1}{c}{ Parameter } & Value \\
\hline Energy per pulse (output) & $25 \mathrm{~mJ}$ \\
Frequency & $10 \mathrm{~Hz}$ \\
Power & $0.25 \mathrm{~W}$ \\
Energy density & $20.83 \mathrm{~J} / \mathrm{cm}^{2}$ \\
Thickness tip & $800 \mu \mathrm{m}$ \\
\hline
\end{tabular}

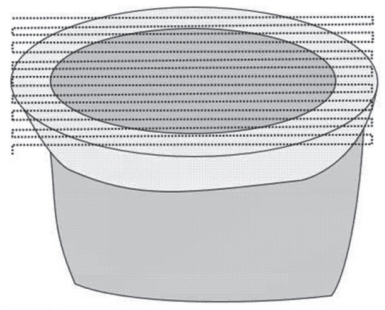

(A)

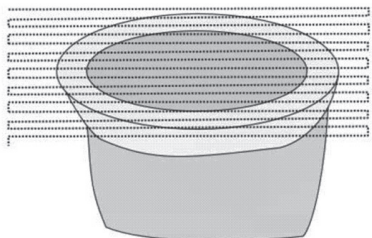

(B)
Fig. 1 Standardization design of the trajectory and irradiation time based on the largest area specimen (A). Therefore, all the specimens could receive the same energy density throughout the dentin area (B).

Norwood, IL, USA). The cross-sectional area of each stick was measured with a digital caliper (Digimatic Caliper Absolute, Mitutoyo, Kawasaki, Japan) and the values were logged into the onboard BlueHill software (BlueHill $^{\circledR}$ Materials Testing Software, Norwood, IL, USA). Subsequently, the sticks were individually attached with a cyanoacrylate-based adhesive (Loctite Super Bonder Gel Control, Henkel, São Paulo, SP, Brazil) to the machine's dispositive (JIG 1 Micro tensile, Odeme, Luzerna, SC, Brazil). The adhesive interface was positioned perpendicular to the tensile forces generated by the testing machine. Tension was applied at crosshead speed of $0.5 \mathrm{~mm} / \mathrm{min}$, with maximum load of $500 \mathrm{~N}$ that measured the force required to test the stick in Newtons $(\mathrm{N})$.

\section{Failure mode analysis}

Both segments of the fractured specimens were evaluated to define the type of failure with a portable digital microscope (Dino Lite Microscope Plus, AnMo Electronics, New Taipei City, Taiwan) at 40× magnification. The specimens were classified by failure modes: adhesive (A); cohesive in dentin (CD); cohesive in resin $(\mathrm{CR})$; and mixed $(\mathrm{M})$, and the percentage of each failure type was obtained.

The methodology used is in accordance with the Guidelines proposed by the Academy of Dental Materials for micro tensile bond strength test ${ }^{33)}$. In each specimen, the fracture area in the both segments of the specimen were estimated. To be categorized as adhesive failure, the adhesive interface must present a separation between the segments for at least $50 \%$ of the area. For classification as cohesive failures in dentin or resin, the interface was not easily notable and one of these cohesive failures must be present at least about $50 \%$ of the area. The fracture was considered mixed if presented more than one type of fracture.

Representative images of each type of fracture were obtained using scanning electronic microscopy (SEM). The fractured sticks were fixed in stubs, coated with gold, and examined via SEM (JSM T220A, JEOL) at a magnification of $\times 75$.

\section{Statistical analysis}

The obtained data was calculated and analyzed statistically with Statistica software (Statsoft ${ }^{\circledR}$, Tulsa, OK, USA). The assumptions of normal distribution and equality of variances were checked for all the variables using Kolmogorov-Smirnov and Levene tests, respectively. As the assumptions were satisfied, the data were subjected to three-way ANOVA $(p<0.05)$ followed by Tukey's test $(p<0.05)$ for individual comparisons.

\section{RESULTS}

The mean bond strengths and standard deviations are listed in Table 3. The data revealed statistical significance for all tested factors $(p<0.0001)$. In addition, the interactions between the factors were significant $(p<0.0001)$ and the interaction of all factors showed a $p$ value of 0.0194 .

For the DBS, initial similar bond strength was observed regardless of pretreatment. When comparison was performed for each DBS with respect to time, all systems treated with no irradiation (control) exhibited stabilized performance. Except for SU, all groups treated with laser irradiation exhibited reduced bond strength after 6 months.

The initial bond strength was similar for all DBSs regardless of pretreatment. However, the 6-month analyses showed that laser irradiation significantly impaired the bond strength of all DBSs except for SU.

For all groups, the adhesive and mixed failure modes were the most common. A description of the distribution is presented in Fig. 2 and representative images of the fractures are shown in Fig. 3 (a to d). 
Table 3 Mean and standard deviations values (MPa) of bond strength

\begin{tabular}{|c|c|c|c|}
\hline \multicolumn{2}{|c|}{ DBS } & \multirow{2}{*}{$\begin{array}{c}\text { Immediate } \\
34.23(2.22) \mathrm{Aa}^{*} \\
30.43(2.67) \mathrm{Aa}^{*}\end{array}$} & \multirow{2}{*}{$\begin{array}{c}6 \text { months } \\
29.58(9.83) \mathrm{Aa}^{*} \\
10.28(5.70) \mathrm{Ba}+\end{array}$} \\
\hline $\mathrm{MP}$ & $\begin{array}{l}\text { Control } \\
\text { Laser }\end{array}$ & & \\
\hline $\mathrm{SB}$ & $\begin{array}{l}\text { Control } \\
\text { Laser }\end{array}$ & $\begin{array}{l}39.43(2.74) \mathrm{Aa}^{*} \\
42.59(6.03) \mathrm{Ab}^{*}\end{array}$ & $\begin{array}{l}31.13(9.57) \mathrm{Aa}^{*} \\
12.99(6.16) \mathrm{Ba}+\end{array}$ \\
\hline CSE & $\begin{array}{l}\text { Control } \\
\text { Laser }\end{array}$ & $\begin{array}{l}36.13(4.27) \mathrm{Aa}^{*} \\
38.93(2.27) \mathrm{Aab}^{*}\end{array}$ & $\begin{array}{l}38.18 \text { (8.90) } \mathrm{Aab}^{*} \\
19.03(8.29) \mathrm{Ba}\end{array}$ \\
\hline $\mathrm{SU}$ & $\begin{array}{l}\text { Control } \\
\text { Laser }\end{array}$ & $\begin{array}{l}42.45(4.87) \mathrm{Aa}^{*} \\
46.62(4.49) \mathrm{Ab}^{*}\end{array}$ & $\begin{array}{l}42.63(8.31) \mathrm{Ab}^{*} \\
40.62(5.27) \mathrm{Ab}^{*}\end{array}$ \\
\hline
\end{tabular}

$n=10, p<0.05$

Different uppercase letters indicate statistical differences for the same condition (DBS and pretreatment) in different time evaluation.

Different lowercase letters indicate statistical differences among the DBSs in the same pretreatment and time.

Different symbols indicate statistical differences for the same DBS and time regarding pretreatment.

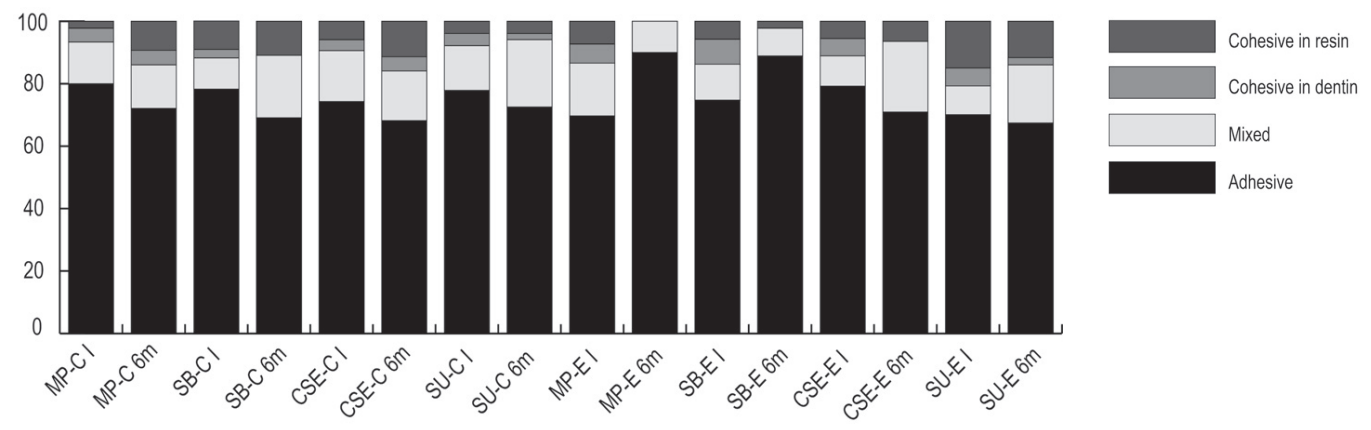

Fig. 2 Failure mode distribution (\%)
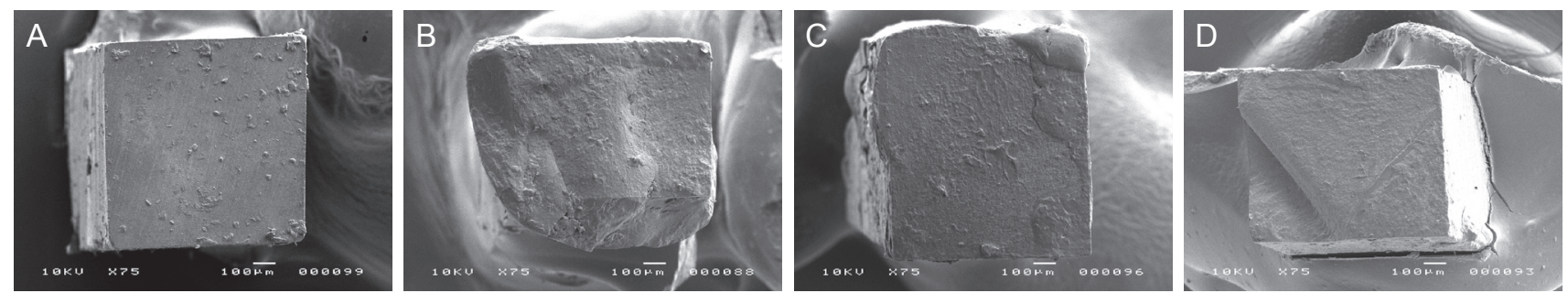

Fig. 3 SEM images of representative fractured types. A: Adhesive. B: Cohesive in dentin. C: Cohesive in resin. D: Mixed.

\section{DISCUSSION}

Universal adhesives were introduced to the market with the goal of simplifying the adhesive technique and reducing technical sensitivity ${ }^{34)}$. However, studies have shown that this new generation of adhesive exhibits different physicochemical properties, resulting in morphological changes in the substrate and improving the longevity of the adhesive interface ${ }^{7,35)}$. To improve its performance, this study investigated the role of the adjunctive use of a multimode universal DBS with Er, Cr: YSGG laser irradiation, as previous studies indicated that this strategy can improve long-term use ${ }^{15-17)}$.

In terms of DBS, the highest bond strength was obtained for SU, showing stable performance over the investigational period. In a systematic review and metaanalysis by Rosa et al. ${ }^{35)}$, the studies that used the same brands, similar modes of self-etching, and storage time exhibited bond strength values similar to those obtained in this study.

Taking control pretreatment into account, all DBS showed stability in the bond strength to dentin when no laser irradiation was applied. However, when the laser was used, a drastic reduction in all conditions after 6 months was observed, except for the SU group.

The best performance for SU with time and pretreatment can be partially attributed to its composition, the phosphate acidified functional 
monomer 10-MDP that forms a stable chemical bond with hydroxyapatite ${ }^{36)}$. This monomer creates stable MDP-calcium salts and a nanolayer interface between hydroxyapatite and MDP that exhibits multifunctional properties, such as durability of nanolayering ${ }^{14,32,36)}$. This protects the hybrid layer due to its hydrophobic nature, prevents collagen degradation, and promotes hydroxyapatite strength to acid dissolution ${ }^{14,32,36)}$.

Despite the promising results presented by the SU, the same did not observed with the CSE, a DBS that also has MDP in its composition. One of the differences between SU and CSE is the presence of the polyalkenoic acid copolymer in SU, commercially known as Vitrebond copolymer, which facilitates the incorporation of the DBS to the hydroxyapatite in the collagen scaffold ${ }^{37}$. This difference deserves further investigation. In addition to these two chemical bonding components, $\mathrm{SU}$ is a simplified adhesive and contains hydroxyethyl methacrylate (HEMA) in the same bottle, which may prevent interfacial self-assembly. These factors were investigated by Tsijumoto et al. ${ }^{7}$ who studied the interfacial characteristics and bond durability of universal adhesives to various substrates. The authors observed that universal adhesives modify the interfacial characteristics of the substrates and create a consistent surface on the dentin ${ }^{7)}$.

Ceballo et al. ${ }^{29)}$ investigated a similar laser (Er: YAG $-2,940 \mathrm{~nm}$ ), in order to condition the dentin and improve the penetration of the adhesive. The results determining that its interaction could result in a poorly attached hybrid layer to the sound dentin below the irradiated area. Other study has shown that the Er, Cr: YSGG laser can affect the hydroxyl ion of hydroxyapatite, causing morphological changes in the structure such as the creation of a rough surface without a smear layer, open dentinal tubules, fissures, and cracks of peritubular dentin ${ }^{18)}$.

Although erbium lasers have similar wavelengths, studies with the Er, Cr: YSGG laser have shown better interaction with the hydroxyl ion $\left(\mathrm{OH}^{-}\right)$presented in hydroxyapatite ${ }^{22,38)}$. The maximum absorption peak of the hydroxyl ion is approximately $2,800 \mathrm{~nm}$, while for water is slightly wider (approximately 2,940 $\mathrm{nm}$ ). Thus, studies suggest that this peak slightly closer to the Er, Cr: YSGG laser wavelength may reflect a better interaction of this laser compared to Er: YAG ${ }^{22,38)}$.

The use of Er, Cr: YSGG has been shown to be an additional method to improve the durability of universal DBS when applied to dentin, but some factors remain unclear since most previous studies did not involve this specific category of adhesive. More recent investigations ${ }^{14,36-37)}$ of the role of the entrapment and chemical reaction of MDP with hydroxyapatite have proposed interesting mechanisms, in which laser interacts with both water and hydroxyapatite, two important components in the establishment of dental bonding.

In the present study, Er, Cr: YSGG laser irradiation was performed on dentin previously impregnated with an adhesive system. The authors speculated that laser treatment, which presents the similar wavelength of water and hydroxyapatite absorption, could eliminate the solvents and water present in the substrate with increasing surface temperature. Some additional studies should be performed to prove this hypothesis. However, based on the results presented herein, no immediate influence on the bond strength values between the control and laser groups was observed. This conflicts with previous studies that used other lasers with different wavelengths and the same technique but obtained an improved adhesive interface ${ }^{15-17,39,40)}$. The controversial result of this study may be because all these studies evaluated the dentin bonding interface immediately after treatment. Despite the promising results regarding $\mathrm{SU}$, questions remain and require further investigation. Another main finding of this study is regarding the MDP-based materials, which can improve the degree of conversion ${ }^{13)}$, indicating that it could minimize the progression of water induced degradation overtime.

For the failure analysis, the methodology used is in accordance with the guidelines proposed by the Academy of Dental Materials ${ }^{33)}$. The most common failure in al groups were adhesive and mixed. For the groups with reduced bond strength, the adhesive failure increased. These results show that procedures that seek to increase the bond strength are interesting, one that reduces the risk of failure in the adhesive interface, increasing the retention of the resin clinically. The obtained results were according to the findings in the literature, validating this analysis ${ }^{2,6,17}$.

\section{CONCLUSIONS}

This study was designed to determine the effect of a universal adhesive on sub-ablative Er, Cr: YSGG irradiated dentin. Based on the results presented herein, it can be concluded that:

The SU was capable of maintaining bond strength after 6 months for the substrate tested.

The sub-ablative laser technique applied on SU did not impair bonding as observed for all other categories of DBS.

\section{ACKNOWLEDGMENTS}

This work was supported by the Coordenação de Aperfeiçoamento de Pessoal de Nível Superior -Brasil (CAPES)-Finance Code 001. The authors also are grateful to $3 \mathrm{M}$ ESPE which donated some of the materials used.

\section{REFERENCES}

1) Pashley DH, Tay FR, Breschi L, Tjäderhane L, Carvalho RM, Carrilho M, et al. State of the art etch-and-rinse adhesives. Dent Mater 2011; 27: 1-16.

2) Giacomini MC, Scaffa P, Chaves LP, Vidal C, Machado TN, Honório HM, et al. Role of proteolytic enzyme inhibitors on carious and eroded dentin associated with a universal bonding system. Oper Dent 2017; 42: E188-E196.

3) Matos AB, Trevelin LT, Silva BTFD, Francisconi-Dos-Rios LF, Siriani LK, Cardoso MV. Bonding efficiency and durability: 
current possibilities. Braz Oral Res 2017; 28: e57.

4) Perdigão J, Kose C, Mena-Serrano AP, De Paula EA, Tay LY, Reis A, et al. A new universal simplified adhesive: 18-month clinical evaluation. Oper Dent 2014; 39: 113-127.

5) Lopes LS, Calazans FS, Hidalgo R, Buitrago LL, Gutierrez $\mathrm{F}$, Reis A, et al. Six-month follow-up of cervical composite restorations placed with a new universal adhesive system: a randomized clinical trial. Oper Dent 2016; 41: 465-480.

6) Martini EC, Parreiras SO, Gutierrez MF, Loguercio AD, Reis A. Effect of different protocols in preconditioning with EDTA in sclerotic dentin and enamel before universal adhesives applied in self-etch mode. Oper Dent 2017; 42: 284-296.

7) Tsujimoto A, Barkmeier WW, Takamizawa T, Wilwerding TM, Latta MA, Miyazaki M. Interfacial characteristics and bond durability of universal adhesive to various substrates. Oper Dent 2017; 42: E59-E70.

8) Marshall GW Jr. Dentin: microstructure and characterization. Quintessence Int 1993; 24: 606-617.

9) Sampaio PCP, Kruly PC, Ribeiro CC, Hilgert LA, Pereira PNR, Scaffa PMC, et al. Comparative bonding ability to dentin of a universal adhesive system and monomer conversion as functions of extended light curing times and storage. J Mech Behav Biomed Mater 2017; 75: 41-49.

10) Chaves LP, Ciantelli TL, Araújo DFG, Giacomini MC, Tjäderhane L, Scaffa PMC, et al. How proteolytic inhibitors interact with dentin on glass-fiber post luting over 6 months. J Mech Behav Biomed Mater 2018; 79: 348-353.

11) Perdigão J, Sezinando A, Monteiro PC. Laboratory bonding ability of a multi-purpose dentin adhesive. Am J Dent 2012; 25: 153-158.

12) Muñoz MA, Luque-Martinez I, Malaquias P, Hass V, Reis A, Campanha NH, et al. In vitro longevity of bonding properties of universal adhesives to dentin. Oper Dent 2015; 40: 282292.

13) Hanabusa M, Yoshihara K, Yoshida Y, Okihara T, Yamamoto $\mathrm{T}$, Momoi Y, et al. Interference of functional monomers with polymerization efficiency of adhesives. Eur J Oral Sci 2016; 124: 204-209.

14) Yaguchi $T$. Layering mechanism of MDP-Ca salt produced in demineralization of enamel and dentin apatite. Dent Mater 2017; 33: 23-32.

15) Gonçalves SE, de Araujo MA, Damião AJ. Dentin bond strength: Influence of laser irradiation, acid etching and hypermineralization. J Clin Laser Med Surg 1999; 17: 77-85.

16) Marimoto AK, Cunha LA, Yui KC, Huhtala MF, Barcellos $\mathrm{DC}$, Prakki A, et al. Influence of Nd:YAG laser on the bond strength of self-etching and conventional adhesive systems to dental hard tissues. Oper Dent 2013; 38: 447-455.

17) Maenosono RM, Bim Júnior O, Duarte MA, Palma-Dibb RG, Wang L, Ishikiriama SK. Diode laser irradiation increases microtensile bond strength of dentin. Braz Oral Res 2015; 29: 1-5.

18) Carvalho AO, Reis AF, de Oliveira MT, de Freitas PC, Aranha $\mathrm{AC}$, Eduardo CP, et al. Bond strength of adhesive systems to Er,Cr:YSGG laser-irradiated dentin. Photomed Laser Surg 2011; 29: 747-752.

19) Ayar MK, Erdemir F. Bonding performance of universal adhesives to Er, Cr: YSGG laser-irradiated enamel. Microsc Res Tech 2017; 80: 387-393.

20) Ayar MK, Yildirim T. Effects of Er,Cr:YSGG Laser pulse frequency on microtensile bond strength to enamel. Oper Dent 2017; 42: 53-61.

21) Garbui BU, de Azevedo CS, Zezell DM, Aranha AC, Matos AB. $\mathrm{Er}, \mathrm{Cr}$ :YSGG laser dentine conditioning improves adhesion of a glass ionomer cement. Photomed Laser Surg 2013; 31: 453460.

22) Ramalho KM, Hsu CY, de Freitas PM, Aranha AC, EstevesOliveira M, Rocha RG, et al. Erbium lasers for the prevention of enamel and dentin demineralization: a literature review.
Photomed Laser Surg 2015; 33: 301-319.

23) Matsumoto K, Hossain M, Hossain MI, Kawano H, Kimura Y. Clinical assessment of Er,Cr:YSGG laser application for cavity preparation. J Clin Laser Med Surg 2002; 20: 17-21.

24) Yazici A, Baseren M, Gorucu J. Clinical comparison of bur- and laser-prepared minimally invasive occlusal resin composite restorations: Two-year follow-up. Oper Dent 2010; 35: 500-507.

25) Cengiz E, Yilmaz HG. Efficacy of erbium, chromiumdoped:yttrium, scandium, gallium, and garnet laser irradiation combined with resin-based tricalcium silicate and calcium hydroxide on direct pulp capping: a randomized clinical trial. J Endod 2016; 42: 351-355.

26) Rizoiu IM, Deshazer LG. New laser-matter interaction concept to enhance hard tissue cutting efficiency. SPIE Proceedings 1994; 2134: 309-317.

27) Jhingan P, Sachdev V, Sandhu M, Sharma K. Shear bond strength of self-etching adhesives to cavities prepared by diamond bur or Er, Cr: YSGG laser and effect of prior acid etching. J Adhes Dent 2015; 17: 505-512.

28) Takada M, Shinkai K, Kato C, Suzuki M. Bond strength of composite resin to enamel and dentin prepared with Er, Cr: YSGG laser. Dent Mater J 2015; 34: 863-871.

29) Ceballo L, Toledano M, Osorio R, Tay FR, Marshall GW. Bonding to Er-YAG-laser-treated dentin. J Dent Res 2002; 81: 119-122.

30) He Z, Chen L, Hu X, Shimada Y, Otsuki M, Tagami J, et al. Mechanical properties and molecular structure analysis of subsurface dentin after Er:YAG laser irradiation. J Mech Behav Biomed Mater 2017; 74: 274-282.

31) Van Meerbeek B, Yoshihara K, Yoshida Y, Mine A, De Munck J, Van Landuyt KL. State of the art of self-etch adhesives. Dent Mater 2011; 27: 17-28.

32) Yoshida Y, Nagakane K, Fukuda R, Nakayama Y, Okazaki M, Shintani $\mathrm{H}$, et al. Comparative study on adhesive performance of functional monomers. J Dent Res 2004; 83: 454-458.

33) Armstrong S, Breschi L, Özcan M, Pfefferkorn F, Ferrari M, Van Meerbeek B. Academy of Dental Materials guidance on in vitro testing of dental composite bonding effectiveness to dentin/enamel using micro-tensile bond strength ( $\mu$ TBS) approach. Dent Mater 2017; 33: 133-143.

34) Cruz J, Sousa B, Coito C, Lopes M, Vargas M, Cavalheiro A Microtensile bond strength to dentin and enamel of self-etch vs. etch-and-rinse modes of universal adhesives. Am J Dent 2019; 32: 174-182.

35) Rosa WL, Piva E, Silva A. Bond strength of universal adhesives: a systematic review and meta-analysis. J Dent 2015; 43: 765-776.

36) Yoshihara K, Yoshida Y, Hayakawa S, Nagaoka N, Irie $\mathrm{M}$, Ogawa $\mathrm{T}$, et al. Nanolayering of phosphoric acid ester monomer on enamel and dentin. Acta Biomater 2011; 7: 31873195.

37) Sezinando A, Serrano ML, Pérez VM, Muñoz RA, Ceballos L, Perdigão J. Chemical adhesion of polyalkenoate-based adhesives to hydroxyapatite. J Adhes Dent 2016; 18: 257265.

38) Apel C, Meister J, Schmitt N, Gräber HG, Gutknecht N. Calcium solubility of dental enamel following sub-ablative Er:YAG and Er:YSGG laser irradiation in vitro. Lasers Surg Med 2002; 30: 337-341.

39) Brianezzi LFF, Maenosono RM, Bim-Júnior O, Zabeu GS, Palma-Dibb RG, Ishikiriama SK. Does laser diode irradiation improve the degree of conversion of simplified dentin bonding systems? J Appl Oral Sci 2017; 25: 381-386.

40) Zabeu GS, Maenosono RM, Scarcella CR, Brianezzi LFF, Palma-Dibb RG, Ishikiriama SK. Effect of diode laser irradiation on the bond strength of polymerized non-simplified adhesive systems after 12 months of water storage. J Appl Ora Sci 2018; 27: e20180126. 